\title{
The Virtual Office
}

M ilton E. M cG iffen, Jr. ${ }^{1}$

Summary. M any careers involve working at multiple locations with unpredictable daily schedules. Professionals may have several locations from which they conduct business. Electronic mail (e-mail) and other features of the Internet have facillitated the evolution of the virtual office, which gives the appearance of a single point of contact with mobile, busy people. E-mail is the most obvious use of the Internet. E-mail groups allow for effective discussions with people of similar interests and the exchange of hard-to-acess expert information. Websites and e-mail groups allow rapid dissemination and discussion of multimedia information. The Vegetable R esearch and Information C enter is an example of how to extend the virtual office concept to the departmental level, allowing spatially scattered researchers, extension workers, and their clientele to work together and exchange information.

Additional IndeX words. I nternet, homepage, website, electronic mail groups, email, Vegetable R esearch and Information Center

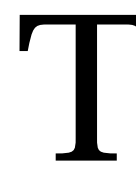

he following articles began as the proceedings of a successful workshop at the 1994 ASH S annual meetings in Corvallis,

$\mathrm{O}$ re. $\mathrm{M}$ embers of the Computer A pplications in $\mathrm{H}$ orticulture Workgroup have since served as reviewers and provided additional articles to expand those proceedings. The Internet has been the central theme and a major facilitator for these papers, as the disparate locations of the contributors made communication via e-mail a necessity.

$M$ any people use e-mail to solve some of the problems created by our fast-paced, mobile society. Professional life has evolved away from the classic model of reporting to an office 5 days a week at the same location from 8 AM to 5 PM. Standard phone conversations can become difficult when users are mobile. Pagers and cellular phones may provide opportunities to communicate from any location, but the respondent may not have the computer files or other references on hand to answer the caller properly. The most effective communication occurs when the questioner can pass on well-reasoned questions and the respondent has the time and resources to focus on an effective answer.

E-mail allows each user to decide when his unpredictable schedule will permit an effective response. $M$ any I nternet users have embraced the concept of a virtual office, which gives the appearance of a single point of contact between people with shifting schedules and locations. The traditional office is static in time and space, and communication between two parties is only possible when their schedules mesh. 
The I nternet makes it easy to exchange messages without knowing the respondant's physical location and schedule. This is not a step backward to the pretelephone daysof the telegraph and postal letters, rather an evolutionary recognition that many professionals have too many conflicting tasks to respond to additional demands at any moment of the day. Electronic communication has unique advantages that make it more powerful, convenient, and efficient than other forms of discourse.

$M$ y use of the Internet began 10 years ago when I was working at the U niv. of Illinois. The number of regular users was small initially, but several of my collaborators checked their e-mail daily. E-mail was especially useful for communicating with people whose time near a telephone was unpredictable or inconvenient. I found that I could get timely responses from people in other countries, which made international collaboration more practical. E-mail wasalso very useful for keeping in touch as I moved away from former colleagues. It can be difficult to connect over the phone with those colleagues who do not live in the Pacific time zone.

Internet use has greatly expanded in the last 5 years. It is now practical to expect that many of the clientele for university information use e-mail regularly. $M$ any faculty at the $\mathrm{U}$ niv. of California have virtual office hours, where students ask questionsthrough e-mail. In addition to convenience, this also allows more effective interchange with other class members, as problems and answers can be rapidly distributed to the entire class without taking time away from mandatory lecture topics. The virtual office concept also works well for an increasing number of my extension clientele. $N$ either my clientelenor myself are in our offices at the same time every day. But the respondent can answer questions as schedules allow and avoid endless hours of returning phone calls to someone's voice mail.

The Vegetable Research and Information C enter (VRIC) has extended the virtual office concept to the departmental level. The U niv. of C alifornia created VRIC to provide a multidisciplinary source of information on vegetables. The center draws on the knowledge of $U$ niversity of California staff from threecampuses, many academic departments, county offices, and field stations. U sers are referred to related information so urces maintained on the World Wide Web by those outside of the university. VRIC's Website (http: Ivrichome. ucdavis.edu) provides a singlepoint of entry to obtain information on all aspects of vegetable production. Selecting the Vegetable Crop I nformation category on the $\mathrm{H}$ omepage (Fig. 1) leads users to a search engine that can retrieve information on a specific crop or a general topic of vegetable production. For example, we frequently receive international phone calls on vegetable production practices in California. VRIC's Website allows downloading of fact sheets and longer publications that give statistics and detailed information on production, pest management, and postharvest practices. M ultimedia information can also be accessed. The Virtual Tour of Vegetable Production provides an on-line slide show of California's vegetable production areas.

VRIC uses e-mail lists to communicate with those inside and outside the university. This is particularly useful when an agriculturally related issue catches the attention of the media. Timely information is provided to the news media and persons likely to be contacted by the news media by e-mailing peerreviewed fact sheets on current issues. When provided with accurate, verified information, the media can work as a partner in carrying out Cooperative Extension's mission of informing the public. VRIC also has an e-mail list called Veghelp. Veghelp allows U niv. of California personnel to discuss specific clientelequestionsor moregeneral to pics. Veghelp inquiries often turn up information on unusual topics that are hidden in someone's files, such as varietal selection for a minor vegetable or control recommendations for a rare pest that has suddenly become a problem. Thus, V eghelp has helped us establish a virtual file cabinet for information that would be otherwise inaccessible.

I have experimented with several other e-mail groups, but have ceased using most of them. Like traditional face-to-face conversations, the value of the information depends on how well the user's needs are matched with knowledge and interests of the other participants. The discussion groups I use most match my extension and research duties. I have found the Veg-Prod discussion group (VanV ranken and Cowgill, 1996) to be very useful in finding answers to unusual grower questions. M ost Veg-Prod users are extension specialists and county agents that ask interesting questions and provide unique information.

I also use e-mail groups that are related to my areas of research expertise. O ne disappointment has been the infrequency of freeranging discussions. This is a common problem with an obvious solution. Thebest group discussions are often lead by aknowledgeable person willing to ask questions that engage the group. Good discussionswill follow if the participants keep building on previous responses and the conversation remains civil. Scientists are often uncomfortable with electronic discussion groups as a way of thinking 


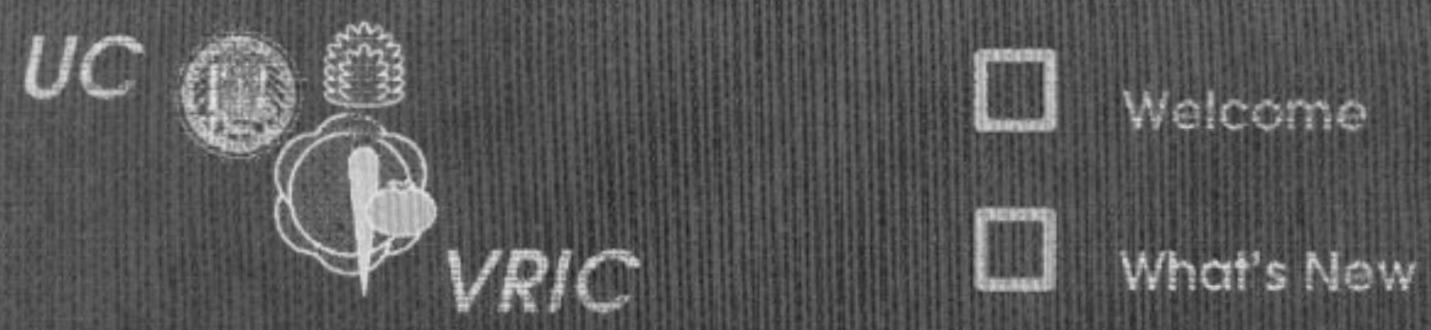

University of Callitomia - Vesetable Reserich and Intomation Center

Welcome to the University of California Vegetable Research and Information Center's (VRIC) World Wide Web Home Page.

About the Vegetable Center

Annual report, annual conference, programs and policies, staff

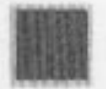

Vegetable Crops Intormation

A database of information relating to vegetable crops

Lssues, News, Events, Bulletin Board

Issues, news and events relating to vegetable crops

Virtual Tour of California Production

Slide tour of vegetable production areas in California

History Food. Fun and Games

Historical pictures, recipes, science fair projects, humor

Other Liseful Sites \& Resources

A collection of helpful resources and useful web sites \& information for students of vegetable crops science

Please sign in at our Visitor Log

Vegetable Research and Information Center. Division of Agriculture and Natural Resources, University of California, All contents copyright. 1996. The Regents of the University of Calitornia. All rights reserved. Developmental funding by the University of California and USDA. CREES. Webmaster: Carol O'Neil. Please email your comments to: 
out loud. Reluctance to participate in discussions can be overcome if questions are directed at specific individuals who can knowledgeably answer aspects of the larger issue. For example, if the general topic is weed seed population dynamics, I may ask an expert in seed pathology what factors lead to seed mortality. O thers will pick up on facets of the answer and add additional insight.

Electronic communication allows for sharing of information in many ways other than via direct contact with the information provider. The M innesota Extension Service uses automated fax and voice-mail services to send out information more effectively and at lower costs than through traditional methods (Whiting 1996). U se of cd-romsto distribute visual information has grown tremendously, and many programs link visual and textual information with computational programsto form powerful databases and problem solving tools (D avis and Gilman, 1996; Kling et al. 1996). Computer simulation programs organizeexpert information from mathematical models into a predictive system. U serfriendly versions of AGNPS (Pantone and Young 1996) and other simulators can berun from distant locations through the I nternet. $\mathrm{M}$ ore programs are also being written as applets, or versions of computer software that can be safely transferred over the Internet. U sers can download an applet and expand it into working size for later use.

I use the Internet to send and receive messagesmorethan for information searches. A popular use of the Internet that I generally avoid is browsing for information (Rhodus and H oskins, 1996). For many users, search agent software has opened up the Internet into a vast library for hard-to-find information (Waldrop, 1994; A uburn, 1996). But, at a university, we have direct access to traditional libraries and experts in many areas. $\mathrm{O}$ ur problem is generally not a lack of information but an overload of data. I nstead of searching for information, I use the I nternet to provide others access to my expertise. VRIC (Fig. 1) and other Websitesallow access to my knowledge by users who would not otherwise have contact with me. The virtual office concept helps make me a more effective communicator by providing wider and more effective dissemination of information and avoids disruption of the research and other activities necessary to create new knowledge.

What does electronic communication portend for the future of agri-industry and university activities? Telecommuting has become popular in many fields. Through com- puter modems workers can conduct their duties from distant locations. In some businesses this has been advanced beyond 1 day a week into a normal work pattern. For example, in a field such as engineering, companies may contract workers thousands of miles away over the Internet. Work then proceeds with regular electronic updates and only occasional face-to-face meetings. Some businesses have done away with conventional office space and only arrange meetings with their consultants as needed.

Telecommuting is possible for some agriculturally related jobs, but is less useful in agricultural production. Agriculture tends to be site-specific. Crop production practices vary with region, as does the impact of the environment. Agricultural production involves many unpredictable factors that need constant reevaluation in light of local conditions. $M$ anaging these factors often requires intuition that can often only be gained onsite. Therewill remain a need for local experts to generate, adapt, and disseminate information. Electronic communication will greatly enhance the exchange of locally collected information but will not eliminate the need for local experts that generate and adapt knowledge for end users.

\section{Literature Cited}

A uburn, J.S. 1996. Sustainable agriculture on the Internet: Practical uses. H ortT echnology 6:325331.

Davis, G.L. and E.F. Gilman. 1996. An electronically based horticultural information retrieval system. H ortT echnology 6:332-336.

Kling, G.J., C.P. Lindsey, and M.E. Zampardo. 1996. UIPLANTS: A software program for the landscape industry and horticulture education. H ortT echnology 6:337-342.

Pantone, D.J . and R .A. Young. 1996. AGN PS: A software program for assessing nonpoint-source pesticide pollution. H ortT echnology 6:343-349.

R hodus, T. and J. H oskins 1996. The Internet: Changing the way horticulturists communicate. H ortT echnology 6:308-314.

VanVranken, R.W. and W.P. Cowgill, J r. 1996. $U$ sing electronic-mail list discussion groupson the Internet to enhance communication in specific commodity groups. H ortT echnology 6:318-324.

Waldrop, M.M. 1994. Software agents prepare to sift the riches of cyberspace. Science 265:882-883.

Whiting, D.E. 1996. INFO-U FAXBACK: Delivering consumer information using fax-on-demand technology. H ortT echnology 6:315-317.

Fig. 1. Introductory homepage to the Univ. of California's Vegetable Research and Information (VRIC) Website. 